Compared to the non-track process, the ASD track achieved 1) reduced default rates of $17.7 \%$, 2) $45 \%$ reduction in psychological assessment duration, 3) $64.4 \%$ reduction in wait time for psychological assessment, 4) 63.3\% reduction in ASD psychological assessment cycle time, 5) 32.8\% reduction in ASD diagnostic process cycle time, 6) $28.1 \%$ reduction in clinic time usage, 7) enhanced case management and delivery of interim intervention services in family-centred manner.

(Illustration - Improvements of ASD Track from Old Process) Conclusions The ASD track improved the diagnostic process and delivery of interim intervention service for Autism Spectrum Disorder in our department.

\section{G457(P) WOULD SOME EMERGENCY ADMISSIONS FROM CHILDREN'S ACCIDENT AND EMERGENCY BE SUITABLE FOR CARE IN THE COMMUNITY?}

J Sutherby, A Ewer, C Clements, C Lemer. Paediatrics, Evelina London Children's Hospital, London, UK

\subsection{6/archdischild-2015-308599.411}

There has been a sharp increase in short-term paediatric admissions over the past decade. Not only is this costly, but could also be detrimental to the children's health; increasing the risk of hospital acquired infections and impacting on their psychological welfare.

The Royal College of Nursing states that 'every child and young person has the right to expect care to be provided at home unless they need to be admitted to a hospital environment' (2009). The aim of this paper was to determine whether any patients either admitted from Children's A\&E or invited to attend a Consultant/SpR led follow-up clinic would have been suitable for discharge and subsequent care at home by children's community nurses. Data was taken from emergency admissions from Children's A\&E into the general paediatric ward for the period $1^{\text {st }}$ May to $30^{\text {th }}$ June $2014(\mathrm{n}=114)$ and attendees to a Consultant/SpR led follow up clinic in paediatric A\&E from $1^{\text {st }}$ June 2014 to $30^{\text {th }}$ June $2014(\mathrm{n}=55)$.

It was found that $13 \%$ of admissions audited would have been suitable for care in the community, equating to 15 patients (Figure 1). An additional 25 patients invited to the follow up clinic would have also been suitable for community care (Figure 2). The skills required from the CCN's were identified; medication administration, recording observations, reassuring

\section{Of the 114 admissions to Mountain ward that we audited, the appropriate management should have been...}

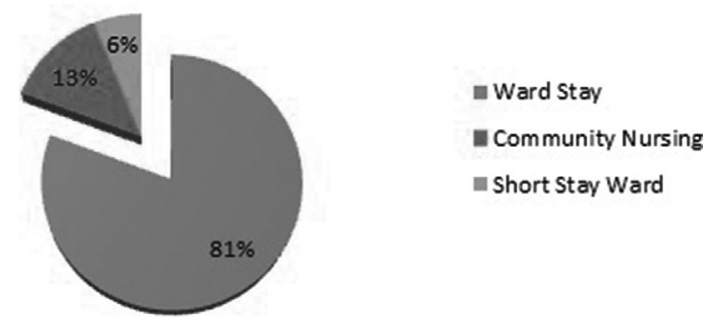

Abstract G457(P) Figure 1 This graph shows the suggested management plan for the patients analysed as a percentage of audited emergency admissions to Mountain ward during the period 1st May to 30th June 2014

\section{Of the patients attending a consultant/SpR clinic...}

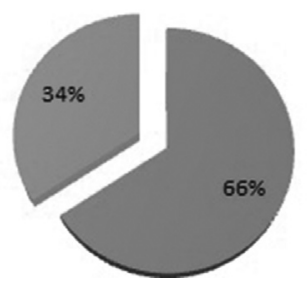

Wuitable for community nursing

Required A\&E clinic review

Abstract G457(P) Figure 2 This graph shows the suggested management plan for the patients analysed as a percentage of audited attendees to a Consultant/SpR led A\&E follow up clinic during the period 1st June to 30th June 2014

and advising patients, performing investigations, changing dressings and relaying test results.

This audit identified an unmet need and showed that the introduction of a CCN service could reduce the number of acute hospital admissions as well as decrease the number of children returning to an A\&E review clinic.

\section{G458(P) CHILD SAFETY WEEK 2014: A QUESTIONNAIRE BASED SURVEY EXPLORING PARENTAL SAFETY PRACTICES AND THE IMPACT OF A COUNTY-WIDE SAFETY CAMPAIGN}

'L Plumb, 'B Cuellar, ${ }^{2} \mathrm{C}$ Sampson, 'I Bennett. 'Department of Community Paediatrics, Gloucestershire Hospitals NHS Foundation Trust, Gloucester, UK; ${ }^{2}$ Gloucestershire Safeguarding Children Board, Gloucestershire County Council, Gloucester, UK

\subsection{6/archdischild-2015-308599.412}

Introduction Unintentional childhood injury is a major public health problem associated with significant mortality. In Gloucestershire there have been several fatal accidents among children related to heavy furniture, blind-cords and nappy bags as well as potentially harmful practices such as co-sleeping. In recent years, UK injury prevention programmes have halved the number of childhood accidental deaths. There is evidence that communitybased campaigns encourage positive behavioural change and can potentially reduce the number of injuries requiring medical attention. Our aim was to explore carer awareness of four specific hazards (nappy sacks, cord blinds, co-sleeping and heavy furniture) linked to paediatric deaths within the region through the use of questionnaires and a standardised educational poster display.

Materials and methods A standardised safety awareness poster board was designed using approved charity leaflets. Six-hundred poster packs were distributed to public centres in Gloucestershire. Additionally, a questionnaire was offered to carers of children attending the Children's centre of Gloucestershire Royal Hospital during Child Safety Week. It explored their current safety practices as well as thoughts on the usefulness and impact of the poster campaign.

Results We obtained 103 questionnaire responses over five days, $96 \%$ of which were from parents. Almost a quarter of respondents were unaware of accidental deaths relating to nappy sacks, although most (82\%) kept sacks out of a child's reach. Of the 57 respondents who had cord blinds at home 26\% did not attach safety devices. Despite prominent national campaigns deterring co-sleeping, $42 \%$ of all respondents had co-slept with their children when aged less than one year old. Two-thirds 